\title{
Busca por modelos de organização do trabalho nos atendimentos primários de saúde do Brasil e de países internacionais no enfrentamento da Covid-19
}

\section{Search for work organization models in primary health care in Brazil and international countries to face Covid-19}

Wellington Pereira Lopes ${ }^{1}$, Ludmila Ichioka² ${ }^{2}$ Viviane Micheli Amaral ${ }^{3}$, Glilciane Morceli ${ }^{1-4}$, Marselle Nobre de Carvalho ${ }^{5}$.

1. Enfermeiro, Especialista em Saúde da Família, discente do Programa de Mestrado em Saúde Coletiva da Universidade Estadual de Londrina. ORCID: https://orcid. org/0000-0001-6997-9980. E-mail: wellingtonp43@gmail.com

2. Farmacêutica, Residência Multiprofissional em Saúde da Família, Universidade Estadual de Londrina, Londrina, Pr, Brasil. ORCID: https://orcid.org/0000-00027848-3386. E-mail: Isilgueiro@gmail.com

3. Enfermeira, Residência Multiprofissional em Saúde da Família, Universidade Estadual de Londrina, Londrina, Pr, Brasil. ORCID: https://orcid.org/0000-0002-0497-1272. E-mail: vivicampanini@hotmail.com

4. Enfermeira. Doutora, docente do curso de enfermagem da Universidade Estadual de Minas Gerais. ORCID: https://orcid.org/0000-0001-8216-9931. E-mail: glilciaane.morceli@uemg.br

5. Farmacêutica, Doutora, docente do departamento de Saúde Coletiva da Universidade Estadual de Londrina. ORCID: https://orcid.org/0000-0001-7338-5448. E-mail: marsellecarvalho@gmail.com

CONTATO: Autor Correspondente: Enf. Wellington Pereira Lopes | Rua Procópio Ferreira, 1045 - Londrina - PR, 86057-010. E-mail: wellington-lopes@outlook.com 
RESUMO No dia 11 de março de 2020, a Organização Mundial da Saúde declarou oficialmente a pandemia da Covid-19. Essa declaração se deu não pela gravidade da patologia, mas pelo grande poder de contágio do vírus causador da doença. Por esse motivo, todos os países se viram frente um novo desafio de saúde mundial tendo a necessidade de se organizar para enfrentar essa nova demanda por meio da criação de novos fluxos, monitoramento interno dos profissionais e pacientes, e monitoramento externo dos mesmos. Além disso, por se tratar de um vírus com novas características, diversas pesquisas foram publicadas em tempo real a pandemia, trazendo novas informações úteis para o trabalho.Por esse motivo, o projeto Safety foi criado com intuito de captar essas novas publicações, avaliar e posteriormente, inserir essas informações no trabalho proporcionando novas ferramentas de enfrentamento de acordo com a aplicabilidade no Brasil.

DESCRITORES: Pandemias. Covid-19. Atenção Primária.

ABSTRACT On March 11, 2020, the World Health Organization officially registered a Covid-19 pandemic. This statement came about not because of the seriousness of the pathology, but because of the great contagion power of the virus, that causes the disease. For this reason, all countries faced a new global health challenge with the need to organize themselves to face this new demand through the creation of the new flows, internal and external professionals monitoring as patients. In addition, because it is a virus with new characteristics, several studies were published in real time on the pandemic bringing new useful information to the work. For this reason, the Safety project was created in order to capture these new publications, evaluate and later, insert this information into the work providing new coping tools according to the applicability in Brazil.

DESCRIPTORS: Pandemic. Covid-19. Primary Health Care. 


\section{INTRODUÇÃO}

1 história revela diversos períodos de epidemias e pandemias decorrente de condições sanitárias e até mesmo devido ao desconhecimento a respeito das etiologias das doenças infecciosas. Algumas epidemias como varíola, tifo exantemático, cólera, malária ou febre tifoide, ficaram marcadas na história devido ao grande número de óbitos deixados até que fosse descoberto algum tratamento ou meio de prevenção1.

Embora a medicina tenha evoluído drasticamente nos últimos anos, algumas epidemias ainda surgem devido a novos agentes infecciosos que emergem em diversos locais. Um grande exemplo desses agentes é a classe dos coronavírus, que se trata de uma família de vírus com seu RNA recoberto por um envelope e que tem um alto poder de contágio em animais e seres humanos².

É um consenso na comunidade cientifica que a família de coronavírus tem quatro tipos de patógenos que causam resfriados comuns em pessoas com imunidade suprimida, além de mais dois tipos de cepas, sendo uma delas, causadora de síndrome respiratória aguda grave, conhecida como SARS-COV, que causou um grande número de óbitos nos anos de 2002 e 2003 na região de Guangdong na China, e outra síndrome respiratória do Oriente Médio, conhecida como MERS-COV que gerou um surto de patologia de vias aéreas na região no ano de $2012^{2}$.

No final de dezembro de 2019, a Organização Mundial de Saúde (OMS) recebeu informações de casos de pneumonia de razão desconhecida, localizados na cidade de Wuhan na China. Inicialmente não haviam informações a respeito do patógeno causador da doença. Posteriormente às ações de saúde, vigilância e monitoramento, foi observado que os pacientes infectados tinham ligações com um mercado atacadista de frutos do mar em Wuhan e após algumas análises de células do epitélio das vias áreas dos pacientes, foi descoberto o sétimo membro da família do coronavírus, também capaz de infectar os seres humanos ${ }^{2-3}$.

Essa nova patologia se espalhou rapidamente por diversos países do mundo, causando diferentes impactos. De acordo com informações oficiais da OMS, em meados de março, já havia mais de 214 mil casos confirmados da doença ao redor do mundo, e por se tratar de um vírus com uma nova característica, não havia nenhum plano concreto de ação para que fosse barrado o crescimento exponencial da doença. Atualmente, no mês de julho, já foram contabilizadas 16.495.309 milhões de casos confirmados da doença e 654.327 óbitos no mundo 4 .

No Brasil, o Ministério da Saúde reconheceu no dia 20 de março, a transmissão comunitária do vírus. Nesse mesmo período, o país contabilizou cerca de 904 casos confirmados em 24 estados do Brasil, tendo 11 óbitos nos estados de São Paulo e Rio de 
Janeiro. Nesta data, do dia 30/09/2020, o número de casos confirmados chega a 4.780.317 milhões e o número de óbitos passa dos 143 mil, isso sem levar em consideração a subnotificação de casos devido à falta de testes para toda população ${ }^{5-6}$.

Essa nova pandemia, além de trazer em debate a deficiência da força de trabalho em saúde, também abre um leque para discussão a respeito da saúde do trabalhador. Segundo o Conselho federal de Enfermagem (COFEN), em maio foram registrados mais de 10 mil casos suspeitos da Covid-19 em profissionais enfermeiros e 100 óbitos por Covid-19. Números que superam os da Espanha e da Itália ${ }^{7}$.

Apesar do grande número de óbitos de profissionais e da realidade da exposição dos mesmos no enfrentamento da COVID-19, pouco se tem discutido sobre a organização do processo de trabalho em saúde frente à pandemia. Ao invés disso, são feitos apenas protocolos de proteção individuais, que apesar de serem de extrema importância, não são suficientes para conter a disseminação coletiva da doença nesse meio ${ }^{5}$.

Sendo assim, pensando na organização do fluxo de trabalho e nas medidas de prevenção e monitoramento dos profissionais atuantes no enfrentamento da pandemia, esse material tem como objetivo relatar a experiência da pesquisa por documentos oficiais que abordem a temática nos diversos países, descrever a organização prévia dos estabelecimentos de saúde, os fluxos adotados e as formas de monitoramento dos profissionais com suspeita de COVID-19, atuante em meio a pandemia para preservar a saúde do trabalhador nesses diversos locais.

\section{MÉTODO}

Estudo descritivo, do tipo relato de experiência, que compartilha a vivência prática do levantamento bibliográfico a respeito da Covid-19 no Brasil e em países internacionais. Estudo proveniente do projeto de extensão intitulado "Projeto SAFETY" que se trata do Estudo das Recomendações de Proteção e Segurança durante a pandemia de COVID-19, cujo objetivo geral é sistematizar as recomendações e as evidências cientificas disponíveis, visando a oferta de informações úteis, corretas, confiáveis, acessíveis e atualizadas sobre as recomendações de proteção e segurança durante a pandemia de COVID-19. O projeto foi desenvolvido por docentes da Universidade Estadual de Londrina em conjunto com alunos da graduação de diversos cursos da saúde, residentes do programa de Saúde da Família e pós graduando de mestrados do programa de Saúde Coletiva.

Inicialmente, o projeto foi dividido em três grupos de estudo e um deles deste ficou responsável por investigar os documentos oficiais, artigos e protocolos a respeito da organização dos processos de trabalho na Atenção Básica, ou em serviços de saúde que prestassem os primeiros atendimentos nos casos suspeitos da doença em diversos 
países. O foco principal foi a organização desse processo com objetivo na prevenção, monitoramento e controle da doença em meio aos profissionais de saúde, porém, devido à dificuldade de encontrar artigos que abordassem o tema na atenção básica, foi optado por explorar apenas os documentos oficiais com a temática a ser explorada.

As pesquisas iniciaram na segunda quinzena de março até a segunda quinzena de maio, onde por meio dos sites oficiais do ministério da saúde de cinco países, foi possível obter cerca de 13 documentos, sendo cinco artigos e oito documentos oficiais sendo eles de países como: Portugal, Espanha, Inglaterra e Estados Unidos.

Após o levantamento bibliográfico, os documentos foram expostos em três quadros para serem sintetizados em formato de texto, facilitando as comparações em relação às ações realizadas entre eles, buscando por meio disto, debater novas formas de organização do processo de trabalho, assim como também, buscar novos formatos de fluxos e de monitorização dos profissionais de saúde.

\section{RESULTADOS E DISCUSSÕES}

\section{Organização prévia dos serviços de saúde}

O surto da COVID-19 impactou os países retratados neste estudo em momentos diferentes devido a contextos políticos e econômicos e as medidas de enfrentamento tomadas por cada local. Devido a rapidez da propagação, muitos dos serviços de saúde não tiveram a capacidade logística de estabelecerem medidas efetivas para 0 enfretamento da doença. Ainda assim, foram encontrados nos documentos, levantados durante a realização desta pesquisa sugestões por parte dos ministérios da saúde de possíveis modos organizacionais como mostra o Quadro 1.

Quadro 1. Organização prévia dos serviços de Saúde

\section{EUA}

Os EUA propuseram a criação de comitês multiprofissionais de enfretamento ao COVID-19, bem com a realização de treinamento sobre atividades respiratórias e sobre a correta higienização das mãos. Recomenda-se também treinamentos quanto ao uso correto de equipamento de proteção individual (EPI), incluindo aventais de mangas compridas, luvas e proteção para os olhos (óculos de proteção), protetor facial descartável, contemplando as orientações de paramentação e desparamentação, cruciais por serem momentos onde há grande risco de contaminação do profissional ${ }^{8}$. 


\begin{tabular}{|c|}
\hline Brasil \\
\hline $\begin{array}{l}\text { No Brasil, além das recomendações similares às encontradas nos documentos americanos, } \\
\text { havia sugestões de criação de fluxos de atendimento na atenção básica de acordo com a } \\
\text { individualidade de cada local e a disponibilização a partir do ministério da saúde de um guia } \\
\text { rápido para Fast track dos casos e orientação para realização de teleatendimento. Além disso, } \\
\text { houve a criação de unidades de referência para atendimento de casos da covid-19 e a criação de } \\
\text { hospitais de campanha, tal estruturação só foi possível devido a relativa demora da chegada e } \\
\text { disseminação massiva do vírus no país. Orienta-se que o serviço de saúde elabore e implemente } \\
\text { um Plano de Contingência, incluindo o gerenciamento dos recursos humanos e materiais e que } \\
\text { desenvolva atividades educativas em saúde visando a redução da exposição a doença. Para } \\
\text { que a educação em saúde não ocorra apenas em ambiente de trabalho, deve-se fortalecer o } \\
\text { relacionamento com líderes comunitários, parceiros de saúde coletiva, universidades, controle } \\
\text { social, conselhos de classe e outros atores que possam apoiar resposta ao CoVID-19 no território, } \\
\text { amplificando a capacidade de disseminação de informações fidedignas }{ }^{9}\end{array}$ \\
\hline Inglaterra \\
\hline $\begin{array}{l}\text { A Inglaterra, por sua vez, cita controles ambientais especiais, como salas de isolamento de } \\
\text { pressão negativa em ambientes de alto risco, nos estágios iniciais de disseminação da doença, } \\
\text { nos quais a capacidade de atendimento torne seu uso viável, visto que elas não são essenciais. } \\
\text { Pacientes com suspeita ou confirmados podem ser isolados nestas salas reduzindo o risco de } \\
\text { disseminação da doença no ambiente. Orienta a realização de treinamentos sobre higienização } \\
\text { correta das mãos e desinfecção correta de ambientes. Também foi disponibilizado teleatendimento } \\
\text { para os usuários com o objetivo de prevenção }{ }^{10-11} \text {. }\end{array}$ \\
\hline Portugal \\
\hline $\begin{array}{l}\text { Portugal realiza plano de contingenciamento, orientando que cada unidade separe uma área } \\
\text { para isolamento de usuários, e fluxo para realizar tal atividade, devendo estar preparada a receber } \\
\text { casos assintomáticos e pessoas desinformadas quanto a doença, ressalta ainda, a necessidade } \\
\text { de uma boa comunicação entre os serviços de saúde para que haja uma continuidade do cuidado, } \\
\text { citando a importância do envolvimento do psicólogo e de assistente social neste momento. Em outro } \\
\text { documento, orienta a organização de teleatendimento para população e implementa a plataforma } \\
\text { "Trace COVID-19" para a gestão de doentes em autocuidados, uma ferramenta de suporte aos } \\
\text { profissionais de saúde dos Cuidados de Saúde Primários, incluindo as Equipas de Saúde Pública } \\
\text { e Autoridades de Saúde, para que, através de um conjunto de tarefas geradas pelo sistema, } \\
\text { promovam o seguimento clínico efetivo e as medidas de Saúde Pública adequadas a doentes com } \\
\text { suspeita ou confirmação de COVID-19, a além de garantir maior proteção aos profissionais pelo } \\
\text { controle dos pacientes a distância, evitando assim, o contato direto com o paciente }{ }^{12} \text {. }\end{array}$ \\
\hline $\begin{array}{l}\text { Espanha } \\
\end{array}$ \\
\hline $\begin{array}{l}\text { Na Espanha, o comando é para que se permita a entrada de pessoas respeitando a } \\
\text { capacidade máxima de cada local de atendimento, devendo o local estar bem sinalizado com } \\
\text { cartazes informativos sobre higienização das mãos, higiene respiratória e controle da tosse. Há } \\
\text { informações também para que haja nessa área de recepção a inserção de dispensadores com } \\
\text { solução à base de álcool, lenços, recipientes descartáveis e de resíduos com tampa de abertura } \\
\text { com pedal, para viabilizar a realização correta da higiene das mãos e respiratória }{ }^{13} \text {. }\end{array}$ \\
\hline
\end{tabular}

Fonte: Elaborado pelos autores (2020). 


\section{Organização do acolhimento e do fluxo de trabalho}

A organização do acolhimento e do fluxo de trabalho foram semelhantes dentre os países estudados. Nota-se que algumas condutas foram copiadas e adaptadas dentro da realidade de cada país, de acordo com a velocidade da propagação da COVID-19. Pode ser observado no Quadro 2 algumas semelhanças e diferenças entre os países apresentados.

Quadro 2. Organização do acolhimento e fluxo de trabalho.

\section{Inglaterra}

$\mathrm{Na}$ Inglaterra, os fluxos de atendimento aos pacientes nas unidades de saúde, pensando no acolhimento e também no cuidado com os profissionais e prevenção de disseminação da infecção, organizaram a entrada dos pacientes com sintomas respiratórios separadamente dos demais, sendo avaliados em salas específicas e sinalizadas para isolamento, de forma a evitar a contaminação cruzada dos demais pacientes na sala de espera e preservar os demais profissionais. Com aumento do número de casos, e com a finalidade de manter a população nas suas casas e evitar o contato direto dos profissionais com o vírus, o fluxo foi alterado, foi introduzido no serviço o tele atendimento ${ }^{11}$.

Para maior segurança dos profissionais, foram adotadas as medidas Standard infection control precautions (SICPs) e Transmission based precautions (TBPs), que respectivamente significam Precaução padrão de controle de infecção e Precauções baseadas em transmissões usados para o manejo de todos os pacientes, sejam eles suspeitos ou confirmados COVID-19. As TBPs são aplicadas quando as SICPs sozinhas são insuficientes para prevenir transmissão cruzada de um agente infeccioso. As TBPs são consideradas cuidados adicionais para controle da infecção e proteção do profissional, mesmo em casos suspeitos. Tais medidas foram adotadas visando a tríade: Infecção, prevenção e precaução de controle ${ }^{11}$.

\section{EUA}

Nos EUA houve separação de profissionais responsáveis pelo atendimento de casos suspeitos e de sinalizar aos demais profissionais esse atendimento. Suspensão de atendimentos de rotina, com foco no covid-19, fluxo esse observado em outros países ${ }^{8}$.

\section{Espanha}

A Espanha priorizou minimizar o máximo possível o número de profissionais em contato com pacientes suspeitos de COVID-19 e reduzir contato entre os profissionais de saúde ${ }^{13}$.

\section{Portugal}

Portugal, assim como a Inglaterra, orientaram a população suspeita de COVID-19 para o autocuidado, sem necessidade de avaliação clínica inicial e presencial, quando apresentam idade inferior a 60 anos. Disponibilizando linhas telefônicas para atendimento complementar aos atendimentos de casos leves ${ }^{12}$. 


\begin{tabular}{|l|}
\hline Brasil \\
\hline No Brasil, apesar dos canais disponíveis para o teleatendimento e da criação de aplicativo do SUS \\
para orientação dos usuários, o fluxo permanece com a busca direta dos sintomáticos nos diferentes \\
locais disponibilizados como referência para o atendimento. No entanto, foram contratados profissio- \\
nais para atuação na linha de frente ao combate à pandemia e disponibilizados protocolos e treina- \\
mentos para organizar o fluxo de acolhimento e atendimento, dinâmico, sendo adaptados constante- \\
mente de acordo com a evolução e descoberta das particularidades do novo coronavírus, com intuito \\
de respaldar os procedimentos evitando a infecção. As Agentes Comunitárias de Saúde (ACS) foram \\
orientadas a manterem suas funções tais como visitas domiciliares para coletar informações clínicas e \\
sociais da população assim como realização de cadastros, no entanto, seguindo as adaptações como \\
questionar antes de adentrar a residência sobre possíveis suspeitos ou confirmados de COVID-19, \\
usar máscaras cirúrgicas, orientar todos os moradores da residência a utilizarem mascaras de tecido \\
e providenciá-las caso não possuam, abrirem portas e janelas e se possível, recebê-las do lado exter- \\
no da residência, além de manterem distanciamento de um metro para casos suspeitos e dois metros \\
para casos confirmados a fim de realizarem a coleta de dados com segurança9
\end{tabular}

Fonte: Elaborado pelos autores (2020).

\section{Monitoramento Interno e Externos dos profissionais de saúde}

Visto o alto poder de transmissão da Covid-19 e os riscos de infecção pela doença em que os profissionais de saúde estão expostos, as formas de monitoramento destes são de extrema importância para evitar a proliferação da doença no ambiente de trabalho, protegendo assim, não apenas os profissionais, mas todos os pacientes que forem atendidos pelos mesmos. Por esse motivo, cada país dentro de sua possibilidade, realizou algum tipo de ação para realizar esse monitoramento conforme apresentado no Quadro 3.

Quadro 3. Monitoramento interno e externo dos profissionais de saúde.

\begin{tabular}{|l|}
\hline EUA \\
\hline Nos EUA o primeiro passo de monitoramento começa com o próprio profissional de saúde, ou \\
seja, o mesmo é orientado a fazer uma sequência de auto monitoramento antes de sair ao trabalho \\
verificando a temperatura, frequência respiratória, frequência cardíaca e os demais sinais vitais. \\
Essa orientação tem como objetivo buscar precocemente alguma alteração no quadro clínico e \\
assim, garantir o distanciamento desse profissional evitando a contaminação dos demais colegas \\
da equipe. Além disso, nos EUA os profissionais que atuam na linha de frente do enfrentamento da \\
Covid-19, tem prioridade no acesso ao teste para a doença, podendo o mesmo, solicitar a testagem \\
quando necessário, e caso o exame seja positivo, o profissional é afastado do ambiente de trabalho \\
e orientado de acordo com sua condição clínica para o isolamento social ou para a internação ${ }^{8}$.
\end{tabular}




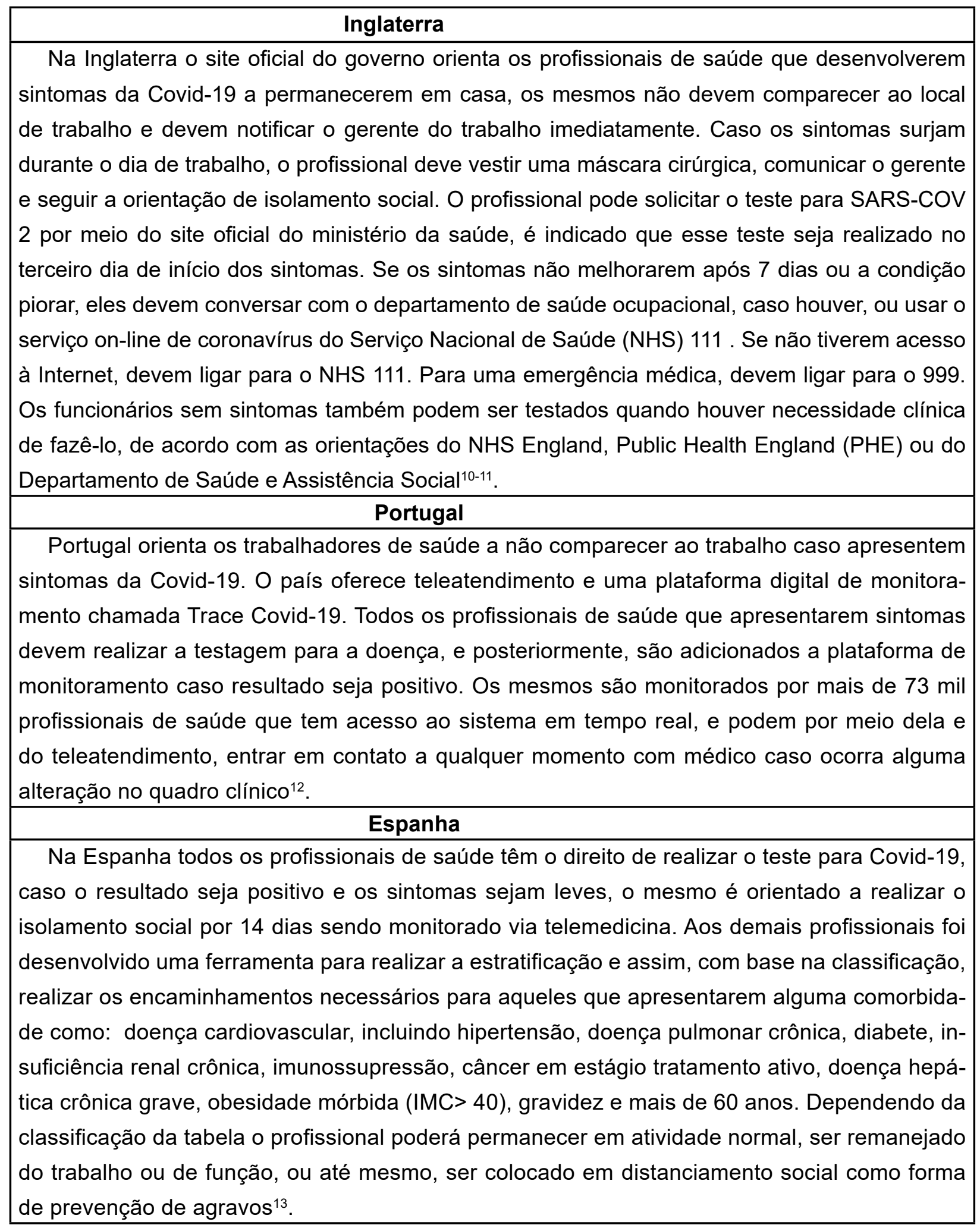




\begin{tabular}{|c|}
\hline Brasil \\
\hline O Brasil por meio do Ministério da Saúde recomenda que sejam progressivamente incluí- \\
dos na rotina de testagem de pessoas sintomáticas os seguintes grupos: profissionais de saúde \\
e segurança pública em atividade, seja da assistência ou gestão, assim como as pessoas que re- \\
sidam no mesmo ambiente que esses profissionais, população acima de 60. a Na Espanha todos \\
os profissionais de saúde têm o direito de realizar o teste para Covid-19, caso o resultado seja po- \\
sitivo e os sintomas sejam leves, o mesmo é orientado a realizar o isolamento social por 14 dias, \\
sendo monitorado via telemedicina. Aos demais profissionais foi desenvolvido uma ferramenta \\
para realizar a estratificação e assim, com base na classificação, realizar os encaminhamentos \\
necessários para aqueles que apresentarem alguma comorbidade como: doença cardiovascu- \\
lar, incluindo hipertensão, doença pulmonar entre outros. O profissional de saúde com suspeita \\
da Covid-19 deve ser afastado imediatamente dos seu posto de trabalho e realizar o teste para \\
doença após sete dias do início. Nesse período é recomendado que o profissional monitore seus \\
sinais vitais e procure um serviço de urgência e emergência caso tenha piora no quadro clínico ${ }^{8}$
\end{tabular}

Fonte: Elaborado pelos autores (2020).

\section{CONSIDERAÇÕES FINAIS}

O processo de pesquisa por documentos oficiais passou por diversos desafios, desde a dificuldade relacionado aos diferentes idiomas, até mesmo pela atualização constante desses documentos, sendo necessário a revisão constante dos achados para assim, atualizar as informações tabuladas para realização desta síntese.

Com relação a organização prévia dos ambientes de trabalho, todos os países citaram a importância em se promover a educação em saúde, além de recomendarem espaços para treinamentos referentes ao uso correto de EPIs, visto o grande número de profissionais contaminados pela Covid-19. Também existe a ênfase na orientação a respeito do adequado gerenciamento dos materiais, devido aos problemas de distribuição de equipamentos e insumos.

No que se refere aos fluxos organizados para proteção dos profissionais e para o enfrentamento da Covid-19, grande parte dos países estudados optaram pela utilização do teleatendimento, evitando assim, contato direto com pacientes com suspeitas da doença, ou até mesmo com aqueles em quarentena devido infecção pela Covid-19. Já os países que não optaram por esse método, optaram pela criação de aplicativos com orientações, e pela criação de unidades de saúde referência no atendimento a casos suspeitas, além de reforçar o direcionamento desses pacientes a um local adequado conforme normas de proteção aos demais pacientes e aos profissionais de saúde.

Relacionado ao monitoramento dos profissionais de saúde, todos os países em teoria, tem disponibilizado testes rápidos para o diagnóstico precoce da doença, e assim, evitar 
a propagação do vírus para os demais profissionais dentro das unidades. Além disso, alguns países disponibilizaram ou disponibilizará consultas médicas e psicológicas via teleatendimento aos profissionais que estão no enfrentamento da doença, buscando assim, garantir a saúde física e psicológicas desses trabalhadores.

Portanto, ficou evidente por meio dessa pesquisa que todos os países se organizaram de acordo com suas possibilidades, e por meio deste resultado, o Brasil também pode adaptar estratégias utilizadas em outras nacionalidades para a realidade local, fortalecendo o SUS e buscando maior efetividade no combate a pandemia.

\section{REFERÊNCIAS}

1. Rezende JM. À sombra do plátano: crônicas de história da medicina [online]. São Paulo: Editor Unifesp, 2009. As grandes epidemias da história. pp. 73-82. ISBN 978-85-61673-63-5. Disponível em: http://books. scielo.org.

2. Zhu D, Zhang D, Wang W, Li X, Yang B, Song J et al. Um novo coronavírus de paciente com pneumonia na China em 2019. The New England Journal of medicine. Disponível em: https://www.nejm.org/doi/ full/10.1056/NEJMoa2001017.

3. Organização Mundial da Saúde. Coronavírus Novel - China . Genebra, Suíça:Organização Mundial de Saúde , 12 de Janeiro de , 2020 . Disponível em:Https://www.who.int/csr/don/12-january-2020-novelcoronavirus-china/en/.

4. Freitas ARR, Napimoga M, Donalisio MR. Análise da gravidade da pandemia de Covid-19. Epidemiol. Serv. Saúde [Internet]. 2020. Disponível em:https://doi.org/10.5123/s1679-49742020000200008.

5. Filho JMJ; Assunção AA; Algranti E; Garcia EG; Saito CA; Maeno M. A saúde do trabalhador e o enfrentamento da COVID-19. Rev. bras. saúde ocup. [Internet]. 2020 [acesso em 2020 ago 01]; 45:e14. Disponível:https://doi.org/10.1590/23176369ed0000120.

6. Brasil. Ministério da saúde. Secretária de Vigilância em Saúde. Covid 19. 2020. Disponível em: https:// covid.saude.gov.br/.

7. Cofen. Conselho Federal de Enfermagem. Registra 10 mil casos de Covid 19 entre profissionais de enfermagem. 2020. Disponível em:http://www.cofen.gov.br/cofen-registra-10-mil-casos-de-covid-19-entreprofissionais-de-enfermagem_79551.html.

8. CDC. Centro de Controle de Doenças Infecciosas. Divisão de Doenças Virais dos EUA. Disponível em:https://www.cdc.gov/coronavirus/2019-ncov/hcp/ambulatory-care-settings.html.

9.Brasil. Ministério da Saúde. Protocolo de Manejo Clínico do Coronavírus (Covid 19) Na Atenção Primária a Saúde Versão 8. Disponível em:http://189.28.128.100/dab/docs/portaldab/documentos/20200422_ ProtocoloManejo_ver08.pdf.

10.UK. Guidance Transmission Characteristics and Principles of Infection Prevention and Control. Public Health England. July 2020. Disponível em: https://w ww.gov.uk/government/publications/wuhan-novelcoronavirus-infection prevention-and-control/transmission-characteristics-and-principles-of-infectionprevention-and-control.

11. UK. Reducing the risk of transmission of COVID-19 in the hospital setting. Public Health England. July 2020. Disponível em:https://www.gov.uk/government/publications/wuhan-novel-coronavirus-infectionprevention-and-control/reducing-the-risk-of-transmission-of-covid-19-in-the-hospital-setting .

12. Portugal. Direção Geral da Saúde. Abordagem do Doente com Suspeita ou Infeção por SARS-CoV-2. Norma $n^{\circ}$ 004/2020 de 23/03/2020 atualizada a 25/04/2020. Disponível em: https://www.dgs.pt/directrizesda-dgs/normas-e-circulares normativas/norma-n-0042020-de-23032020-pdf.aspx 
13. Espanha. Ministerio de Sanidad. Procedimiento de Actuación para los Servicios de Prevención de Riesgos Laborales frente a la Exposición AL SARS-cov-2. Junho, 2020.Disponivel em: https://www.mscbs. gob.es/profesionales/saludPublica/ccayes/alertasActual/nCov-China/documentos/PrevencionRRLL_ COVID-19.pdf

RECEBIDO: $28 / 07 / 2020$

ACEITO: $15 / 10 / 2020$ 